\title{
Hybrid manufacturing of titanium Ti-6Al-4V combining laser metal deposition and cryogenic milling
}

\author{
Juliane Moritz $^{1}$ - André Seidel ${ }^{1} \cdot$ Michael Kopper ${ }^{2}$. Jörg Bretschneider ${ }^{1} \cdot$ Johannes Gumpinger $^{3} \cdot$ Thomas Finaske $^{1}$. \\ Mirko Riede ${ }^{1}$ - Michael Schneeweiß ${ }^{2}$ - Elena López ${ }^{1}$. Frank Brückner ${ }^{1,4}$. Christoph Leyens ${ }^{1,5} \cdot$ Thomas Rohr $^{3}$. \\ Tommaso Ghidini ${ }^{3}$
}

Received: 18 November 2019 / Accepted: 13 March 2020 / Published online: 1 April 2020

(C) The Author(s) 2020

\begin{abstract}
Hybrid manufacturing, which, e.g., combines additive manufacturing with conventional machining processes, can be a way of overcoming limitations currently encountered in additive manufacturing. Cryogenic milling might be a viable option for hard-tocut materials, as it leaves a contamination-free surface and can increase surface quality and tool life compared to conventional cooling concepts. In this study, the influence of cryogenic milling with carbon dioxide on titanium Ti-6Al-4V specimens manufactured with laser metal deposition (LMD) was investigated regarding tool wear and surface integrity in comparison to dry machining and machining with cooling lubricants. Moreover, additional layers of material were deposited on top of conventionally and cryogenically machined surfaces by means of LMD. The interface zone was then examined for defects. The milling process was closely monitored by means of thermal and high-speed imaging. Optical and tactile surface analysis provided evidence that lower roughness values and improved surface qualities could be obtained with cryogenic machining in comparison to dry machining. Moreover, significantly less tool wear was observed when a cryogenic cooling medium was applied. Although the utilization of conventional cooling lubricants resulted in satisfying surface qualities, substantial residual contamination on the milled surface was detected by means of fluorescence analysis. These contaminants are suspected to cause defects when the next layer of material is deposited. This is supported by the fact that pores were found in the weld bead applied on top of the milled specimens by means of LMD. Conversely, cryogenic machining resulted in very clean surfaces due to the residue-free evaporation of the coolant. Hence, a good metallurgical bonding between the weld bead and the milled substrate could be achieved. The results indicate the great potential of cryogenic milling in hybrid manufacturing, especially in terms of intermediate machining, as it provides residue-free surfaces for subsequent material deposition without an additional cleaning step and can significantly prolongate tool life.
\end{abstract}

Keywords Cryogenic machining $\cdot$ Hybrid manufacturing $\cdot$ Laser metal deposition $\cdot$ Titanium alloy

Juliane Moritz

Juliane.Moritz@iws.fraunhofer.de

1 Fraunhofer Institute for Material and Beam Technology, Winterbergstraße 28, Dresden, Germany

2 Westsächsische Hochschule Zwickau, Dr.-Friedrichs-Ring 2A, 08056 Zwickau, Germany

3 ESA/ESTEC, European Space Research and Technology Center, 2201 Noordwijk, AZ, Netherlands

$4 \quad$ Luleå University of Technology, 97187 Luleå, Sweden

5 Technische Universität Dresden, Helmholtzstr. 7, 01069 Dresden, Germany

\section{Introduction}

Additive manufacturing technologies have been taking root in various high-performance applications, such as aerospace industries or the biomedical sector [1-3]. Nevertheless, major limitations still exist, especially with respect to accomplishable surface qualities, due to, e.g., the so-called staircase effect. The staircase effect is caused by the layer-wise approximation of the component geometry and is predominantly affected by the layer thickness and the inclination angle $[4,5]$.

One possibility for enhancing the precision of a component while at the same time maintaining the flexibility of additive manufacturing processes is the combination of additive 
manufacturing with a subtractive machining operation (hybrid manufacturing) [5, 6]. Machining is possible both between the deposition of individual layers as intermediate machining or as a finishing step. Intermediate machining is especially important for manufacturing components containing cavities, undercuts, or other segments that cannot be accessed at a later stage [7]. However, this approach poses particular challenges to the machining of hard-to-cut materials such as titanium and its alloys, which are commonly used in additive manufacturing $[8,9]$.

The reasons for the poor machinability of these alloys lie in their physical and chemical properties. The high mechanical strength is maintained even at elevated temperatures during machining, which results in plastic instability localized in adiabatic shear bands in the material [10] and significant heat release at the interface between tool and chip. According to Hong et al. [11], temperatures of more than $1000{ }^{\circ} \mathrm{C}$ can be reached. Due to the low thermal conductivity of titanium, the heat released in the process zone can only be dissipated slowly, which leads to rapid tool wear and requires efficient cooling during machining. Several researchers have reported that only about 20 to $25 \%$ of the heat generated during machining of the titanium alloy Ti-6Al-4V is dissipated by the produced metal chips, whereas 75 to $80 \%$ of the heat transfer occurs through the tool [12]. Moreover, titanium tends to weld to the tool as a result of its pronounced chemical reactivity [11]. This problem is even more pronounced for milling than for turning operations [13].

Hence, dry machining is often not economically reasonable for these materials due to high tool wear and unsufficient surface quality $[11,14]$. Therefore, conventional cooling concepts based on mineral oils, such as emulsion cooling or minimum quantity lubrication (MQL), are mostly used for effective heat dissipation and friction reduction. The utilization of such cooling lubricants, however, leads to organic residues on the part surface and frequently entails extensive cleaning procedures $[15,16]$. Furthermore, recent studies have shown that these cooling lubricants are associated with both health and environmental concerns. Skin irritations, respiratory diseases, and even cancer might be connected to the exposure to conventional cutting fluids. In addition, many conventional cooling lubricants are classified as environmentally hazardous and are therefore expensive to dispose and recycle $[17,18]$. A potential sustainable and physiologically harmless alternative is the use of cryogenics, primarily carbon dioxide or nitrogen at very low temperatures, which can take over the function of cooling [17-19]. Liquid carbon dioxide, which was used in this study, can be stored at room temperature in high pressure containers (60 bar). When the $\mathrm{CO}_{2}$ exits through a nozzle, it expands rapidly and undergoes phase transformation from the liquid phase to a mixture of gaseous and solid carbon dioxide. The latter sublimates at a temperature of $-78.5^{\circ} \mathrm{C}[20,21]$.

The main advantage of using cryogenic gasses for machining operations is the residue-free evaporation or sublimation.
This facilitates very clean surfaces for the component and metal chips being free of contamination and recyclable [17-19]. The reduced thermal load of tool and workpiece minimizes wear and significantly increases tool life, as proven in several studies [17, 22, 23].

The achievable results of cryogenic machining largely depend on the cutting parameters and the supply of the cryogenic medium. Analogous to conventional coolants, cryogenics can be fed to the process zone as external jets via flexible hoses, or internally through the tool spindle and the tool, thus influencing turnover, quantity, and reproducibility of the heat transfer.

In addition to this, it was confirmed by numerous studies that cryogenic machining not only does substantially increase the machinability of hard-to-cut materials but also does improve the obtainable surface integrity [17, 19, 24-27]. Lower roughness values could be achieved in comparison to emulsion cooling and dry machining [27]. Furthermore, the considerable cooling effect results in a rise in micro-hardness and compressive stresses in the outer layer of the workpiece, thus frequently leading to an enhanced wear resistance [25]. Positive effects on fatigue behavior and corrosion resistance were also reported [17, 26, 28].

The purpose of this paper is to investigate the effects of cryogenic milling as an intermediate machining step on titanium components manufactured by means of laser metal deposition (LMD) with powder. LMD with powder is an additive manufacturing process which is characterized by the layer-wise deposition of single weld beads. Powder material is fed into the process zone via a gas stream, where it is preheated by a laser and resorbed by the laser-induced melt pool. This technology enables the fabrication of complex and large-sized components. Nevertheless, the achievable surface quality is limited due to the staircase effect, the inherent waviness, and particle adhesions as a consequence of the base material, track overlap, and the layer-wise buildup. More near net shape can be achieved via reduced layer thickness, a higher degree of overlap and smaller powder particles; however, this is associated with a drop in productivity.

Hybrid manufacturing in terms of LMD and cryogenic milling, by contrast, offers the potential to trade off productivity, finished part quality, and environmental aspects in a superior way. In fact, this approach allows to achieve desired surface qualities in areas which are not accessible by post-processing, thus enabling results which would not be possible with the individual processes in isolation. As an example, potentially crack-inducing surface structures can easily be removed [6].

Moreover, intermediate machining steps are often required for functional integration [29] or multi-material applications [30], which are associated so far with intermediate cleaning [31]. Milling of the side surfaces enhances the surface quality of the final component, whereas milling of the top surfaces helps to ensure continuous increase in height while providing 
a reproducible surface condition for the subsequent material deposition, respectively [32]. A further important aspect lies in the field of quality control and assurance where a defined number of layers with exactly defined surface conditions can be examined and evaluated to detect defects at an early stage and repair them immediately. As an example, Karunakaran et al. [33] found that a surface oxide layer could thus be removed, which otherwise would have had a negative impact on the build process. Moreover, Du et al. [34] used integrated eddy current measurements to detect defects, which could then be removed during the next machining step and directly be replaced with new material.

The simplified principle of hybrid manufacturing with LMD and these two different milling strategies, i.e., milling of the side surfaces or the top surfaces, are displayed in Fig. 1, respectively.

Again, deviating from evaporating substances like liquid nitrogen or solid carbon dioxide (dry ice), the use of conventional cooling lubricants leads to residues which remain on the surfaces of the component. Yan et al. [35] investigated the influence of oil- and water-based cooling lubricants on the material properties of a Ti-6Al-4V component manufactured in a hybrid approach combining LMD and machining. In the case of material deposition on intermediate machined surfaces without an appropriate cleaning procedure, significant contamination and pronounced cracking were observed. In fact, a multistage cleaning process consisting of laser heating and cleaning with compressed air was applied to ensure a reliable hybrid manufacturing process [35]. A study by Cortina et al. using Inconel 718 reported similar results. LMD on surfaces which were contaminated with cooling lubricants leads to substantial porosity in the deposited weld beads unless extensive laser cleaning was applied prior to the additive manufacturing step [36].

The present study, by contrast, focusses on evaluating the suitability of cryogenic milling with $\mathrm{CO}_{2}$ for hybrid manufacturing of Ti-6Al-4V [37] and comparing the results to those obtained with dry machining and conventional cooling concepts.

\section{Experimental approach}

Hybrid manufacturing experiments were carried out in a customized manufacturing cell which comprises equipment for LMD and milling as well as metrological instruments and smart process control systems. Within this manufacturing cell, an ABB IRB 4400 multi-axis robot is used for LMD with powder, whereas intermediate and final milling operations
Fig. 1 Principle of hybrid manufacturing including laser metal deposition and cryogenic milling with internal coolant supply on side surfaces (above) and top surfaces (below) (The interaction zone between the tool and the workpiece is marked by a red dot)

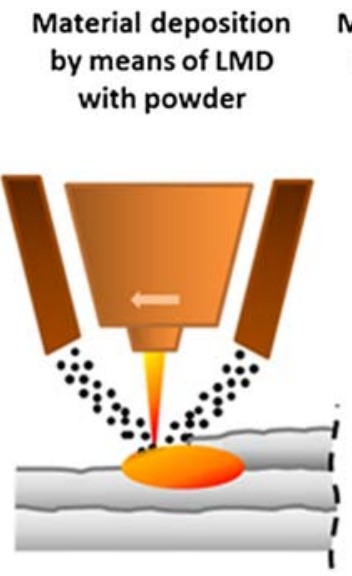

Milling of side surfaces with internal cryogenic cooling
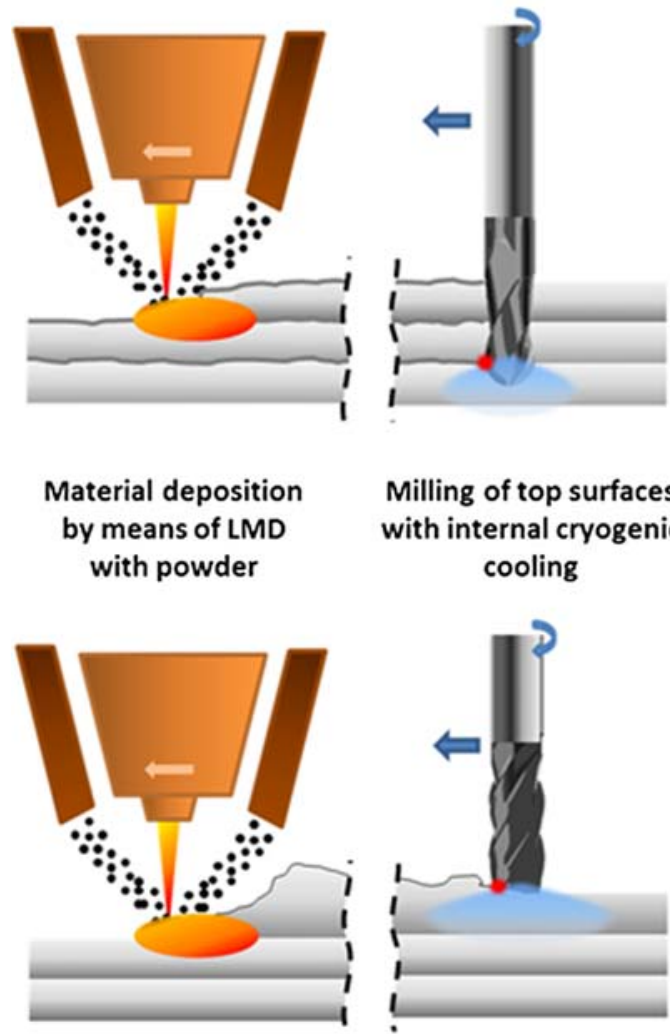

Milling of top surfaces with internal cryogenic cooling

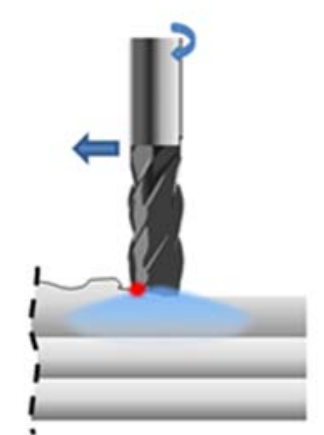

Cryogenic milling of additively manufactured structure

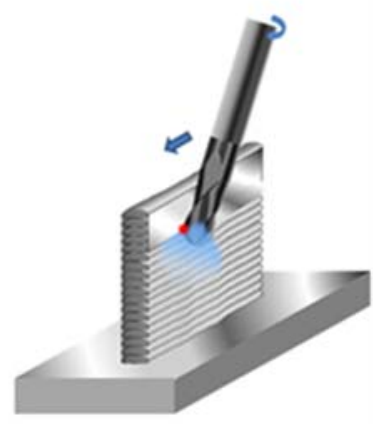

Cryogenic milling of additively manufactured structure

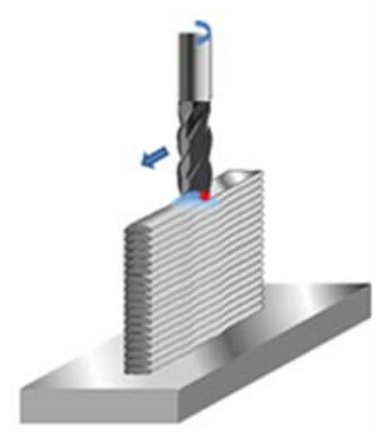


are performed by an ABB IRB 6660 robot. The option for cryogenic milling is implemented through a Rother Technology GmbH AEROSOL MASTER 4000cryolub® coolant supply system which facilitates the use of liquid carbon dioxide as a coolant. The milling robot is equipped with a Diebold milling spindle HSG-S-180 with a 0.8 -mm diameter lance for internal coolant supply. The setup with the two robots in the hybrid manufacturing cell is illustrated in Fig. 2 .

Test specimens were manufactured by means of LMD using a Laserline LDF 2000 laser and a COAXpowerline nozzle with argon and helium as shielding gasses [38]. Titanium Ti-6Al-4V ELI powder (Arcam AB) with a particle size distribution of $45-100 \mu \mathrm{m}$ was used as feedstock material. An optimized set of parameters was used, which had been adjusted for this titanium alloy in the previous studies [38]. The process parameters are listed in Table 1.

Specimens were built up on substrate plates of the same material. These substrates were fixed with clamping jaws to ensure sufficient mechanical stability during the whole process.

For basic milling experiments, a wall geometry with a thickness of approximately $10 \mathrm{~mm}$ and a length of $90 \mathrm{~mm}$ was built up to a height of $70 \mathrm{~mm}$.

Since tool wear should be investigated for longer machining processes, it was necessary to use larger structures for these experiments. Hence, cuboid samples with an edge length of $20 \mathrm{~mm} \times 30 \mathrm{~mm}$ and a height of $70 \mathrm{~mm}$ were manufactured.

The specimens were then divided into different sample groups. The aim was to analyze the effect of different $\mathrm{CO}_{2}$ throughputs in comparison to dry milling and machining with conventional cutting fluids (Cimcool Industrial Products B.V., Cimstar MB603). Moreover, both milling of the side surfaces and the top surfaces (referred to as "side" and "top" in the sample number) were investigated (see Fig. 1). An overview of the investigated milling parameters is given in Table 2.

Dry machining and cryogenic machining were carried out on samples in the as-built condition (no stress relief, no heat treatment, or hot isostatic pressing). Cryogenic milling was performed in the hybrid manufacturing cell (see Fig. 2), whereas conventional milling had to be conducted on an enclosed CNC milling machine due to the risk of contamination by conventional cutting fluids. For this purpose, an AVIA FNE $40 \mathrm{~N}$ CNC milling machine was used.

Milling of the side surfaces was performed in order to study the impact of the milling parameters on surface integrity. An Ingersoll CHIP SURFER D12 ball nose cutter with three flutes (product no. 46B12009T8RB17 IN2005, coated with TiAIN) with internal cooling was used for this purpose. For better accessibility of all parts of the workpiece, the tool was tilted by an angle of $15^{\circ}$. Two different cutting speeds, which consequently lead to differences in thermal release, were investigated.

For assessing the influence of surface cleanliness and potential organic residues on subsequent additive material deposition, specimens were face milled on the top surface utilizing a Duo-Lock ${ }^{\mathrm{TM}}$ HAIMER MILL HF Series - H2004UK D12 end mill with four teeth with internal cooling.

In total, four different carbon dioxide flow rates, which can be adjusted as percentage values at the coolant supply system, were examined. The corresponding mass flows as derived from the weight change of the gas container are also specified in Table 2.

In contrast to using $\mathrm{CO}_{2}$ as a cooling medium, the mineral oil-based cooling lubricant Cimstar MB603 (5 vol\% in water) was used for conventional milling. Samples did not undergo any cleaning procedure after machining in order to analyze potential organic residues on the workpiece surface.

Tool wear during cryogenic machining in comparison to dry cutting was investigated based on the milling parameters D-100-side and C45-100-side (see Table 2). A new milling tool was inserted prior to each experiment. The length of the milling path was set to $90 \mathrm{~m}$ with the tool being permanently engaged, allowing the tool to reach operating temperatures which are representative for longer milling processes. In the case of dry machining, the experiment was aborted prematurely due to tool failure. Tool wear was then analyzed by means of SEM imaging using a JEOL JSM-6610LV microscope.
Fig. 2 Hybrid manufacturing cell with two robots for laser metal deposition (right) and cryogenic milling (left)

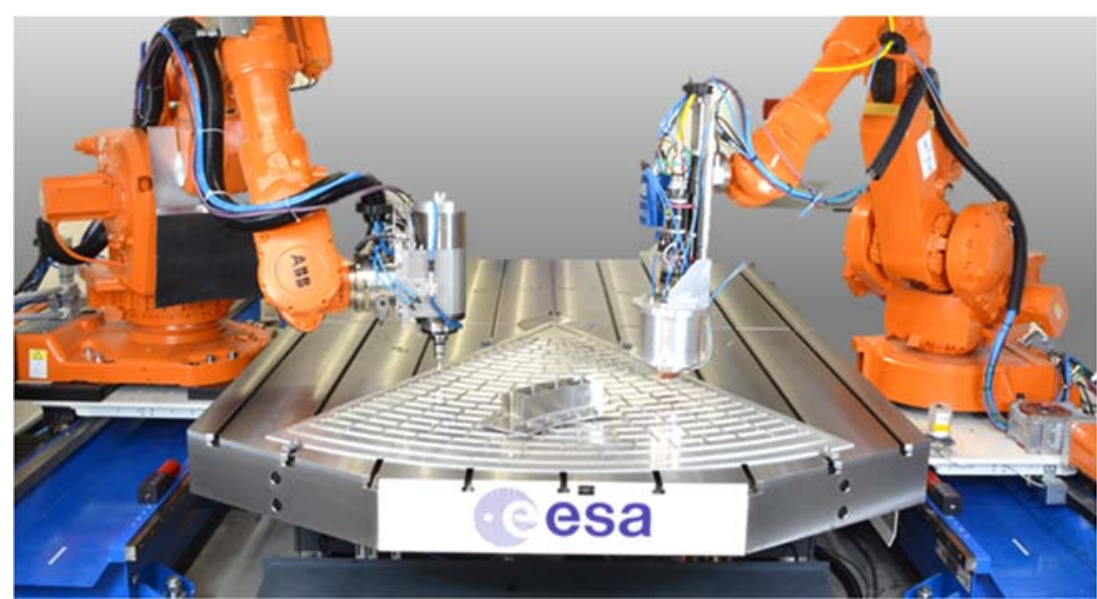


Table 1 Overview of parameters for LMD of Ti-6Al-4V thin walls

\begin{tabular}{llll}
\hline Laser power $(\mathrm{W})$ & Feed rate $(\mathrm{mm} / \mathrm{min})$ & Spot diameter $(\mathrm{mm})$ & Powder mass flow $(\mathrm{g} / \mathrm{min})$ \\
\hline 1600 & 400 & 5 & 11 \\
\hline
\end{tabular}

The milling process was monitored using an infrared camera (Optris PI 640) for thermal imaging. The emission coefficient of the milling tool was determined to be 0.975 in comparison to an ideally black surface. A temperature range from 0 to $250{ }^{\circ} \mathrm{C}$ was selected for the measurement. Moreover, a high-speed recording system (Mikrotron MotionBLITZ LTR3.0, EoSens 3CXP-5 camera) at a framerate of $2500 \mathrm{fps}$ and a shutter speed of $397 \mu \mathrm{s}$ was applied. The recordings were performed with a $50 \mathrm{~mm} /$ F2.0 camera lens.

Surface roughness was evaluated both by means of tactile and optical measuring methods. Tactile roughness measurements were performed according to ISO1997/2009 on five randomly selected spots per sample with a SURFCOM TOUCH 50 (Accretech Europe $\mathrm{GmbH}$ ) surface measuring device. A probe with a tip radius of $2 \mu \mathrm{m}$ was used. The evaluation length was set to $30 \mathrm{~mm}$ at a measuring speed of $0.60 \mathrm{~mm} / \mathrm{s}$. Optical roughness analysis was carried out with a KEYENCE VK-X250K/260 K confocal laser scanning microscope on five randomly selected images per surface. The roughness was calculated from each of ten parallel scanning lines on three spots per image. A Gaussian filter with a cutoff value of $\lambda_{\mathrm{s}}=8 \mu \mathrm{m}$ and $\lambda_{\mathrm{c}}=2.5 \mathrm{~mm}$ was applied for both measuring methods.
For investigating the cleanliness of the parts' surfaces obtained by milling with cryogenic cooling, with conventional cooling lubricants, and under dry conditions, the SITA CleanoSpector was utilized. Its measuring principle is based on fluorescence measurement of surface contaminants. For calibration, a Ti-6Al-4V part was cleaned in ethanol in an ultrasonic bath for $20 \mathrm{~min}$. It was then assumed as an ideally clean reference part for the subsequent measurements. Immediately after cleansing, calibration was performed on five different spots on the surface. The cleanliness level was then determined on 15 spots on each of the samples D-100top, C45-100-top, and CL-100-top, respectively. Two specimens per sample group were analyzed.

After the degree of contamination had been investigated, two tracks of titanium were deposited on top of each of the three sample groups by means of LMD, applying the same parameters that had been used previously for additive sample manufacturing.

Metallographic cross sections of the deposited tracks were prepared for assessing the metallurgical bonding of those layers to the additively manufactured substrate and for identifying any inclusions or porosity caused by the coolant residues. Five micrographs of each weld track were analyzed using an OLYMPUS GX51 optical microscope.

Table 2 Overview of sample groups and investigated milling parameters (abbreviations: D - dry, C - cryogenic, CL - cooling lubricant)

\begin{tabular}{|c|c|c|c|c|c|}
\hline Sample no. & Coolant strategy & $\begin{array}{l}\text { Mass flow of } \mathrm{CO}_{2} \\
\left(\mathrm{~kg}^{*} \min ^{-1}\right)\end{array}$ & $\begin{array}{l}\text { Cutting speed } \mathrm{v}_{\mathrm{c}} \\
\left(\mathrm{m}^{*} \min ^{-1}\right)\end{array}$ & $\begin{array}{l}\text { Width of cut } \mathrm{a}_{\mathrm{e}} \\
(\mathrm{mm}) / \text { depth of cut } \mathrm{a}_{\mathrm{p}}(\mathrm{mm})\end{array}$ & $\begin{array}{l}\text { Feed per tooth } \\
\mathrm{f}_{\mathrm{z}}(\mathrm{mm})\end{array}$ \\
\hline D_100_side & Dry & 0 & 100 & $1 / 1$ & 0.075 \\
\hline D_115_side & & & 115 & & 0.075 \\
\hline D_100_top & & & 100 & & 0.1 \\
\hline C30_100_side & $30 \% \mathrm{CO}_{2}$ & $0.04 \pm 0.03$ & 100 & & 0.075 \\
\hline C30_115_side & & & 115 & & 0.075 \\
\hline C45_100_side & $45 \% \mathrm{CO}_{2}$ & $0.16 \pm 0.03$ & 100 & & 0.075 \\
\hline C45_115_side & & & 115 & & 0.075 \\
\hline C45_100_top & & & 100 & & 0.1 \\
\hline C70_100_side & $70 \% \mathrm{CO}_{2}$ & $0.26 \pm 0.03$ & 100 & & 0.075 \\
\hline C70_115_side & & & 115 & & 0.075 \\
\hline C100_100_side & $100 \% \mathrm{CO}_{2}$ & $0.32 \pm 0.06$ & 100 & & 0.075 \\
\hline C100_115_side & & & 115 & & 0.075 \\
\hline C100_100_top & & & 100 & & 0.1 \\
\hline CL_100_side & Mineral oil-based emulsion & 0 & 100 & & 0.075 \\
\hline CL_115_side & & & 115 & & 0.075 \\
\hline CL_100_top & & & 100 & & 0.075 \\
\hline
\end{tabular}


In an attempt to determine the depth of deformation or thermal impact caused by machining, metallographic cross sections of the side-milled specimens were also prepared. Because resolution in an optical microscope proved insufficient to detect any deformed layer, the polished and etched samples were coated with carbon in a sputter coater and analyzed in a JEOL JSM-6610LV scanning electron microscope.

An overview of the consecutive steps of the experimental procedure is illustrated in Fig. 3.

\section{Results and discussion}

\subsection{Process monitoring}

By means of thermal and high-speed imaging, the cryogenic milling process could be closely monitored. In Fig. 4, still images extracted from the process videos at two different flow rates of $\mathrm{CO}_{2}$ (samples C45-100-side and C100-100-side) in comparison to dry machining (D-100-side) are presented. Moreover, the metal chips from the process were visually analyzed and are also depicted in Fig. 4.

It is evident from Fig. 4a-1 that in case of dry machining, the process heat led to an excessive heating of the tool. This is undesirable since it can entail premature tool wear. Wear might also be promoted by the buildup edge formed on the cutting edge, as illustrated in Fig. 4a-2. Titanium shows a strong tendency to adhere or weld to the applied tool during milling [11].

In contrast to dry cutting, the infrared images recorded during cryogenic machining prove that the tool itself remained cold and was transformed into an effective heat sink (see Fig. 4b-1, c-1). On the other hand, the metal chips in the thermal image exhibit an elevated temperature and obviously contribute to heat dissipation. The cryogenic medium also had a strong cooling effect on the workpiece (see Fig. 4c-1), resulting in icing of the component at higher gas flow rates. As a consequence, condensed water formed on the part surfaces. However, condensation should be kept at a minimum or preferably be avoided from the viewpoint of process reliability, even though it is yet unclear whether these water droplets can have any impact on the hybrid manufacturing process or the component properties. Moreover, excessive cooling might entail geometrical distortion of the workpiece due to thermal contraction and thus impair precision if not considered appropriately.

Icing could also be observed on the milling tool. This effect was more pronounced for higher flow rates, where only the cutting edge remained free of ice. Figure 4 b-2 indicates that the metal chips tended to stick in the space between the cutting

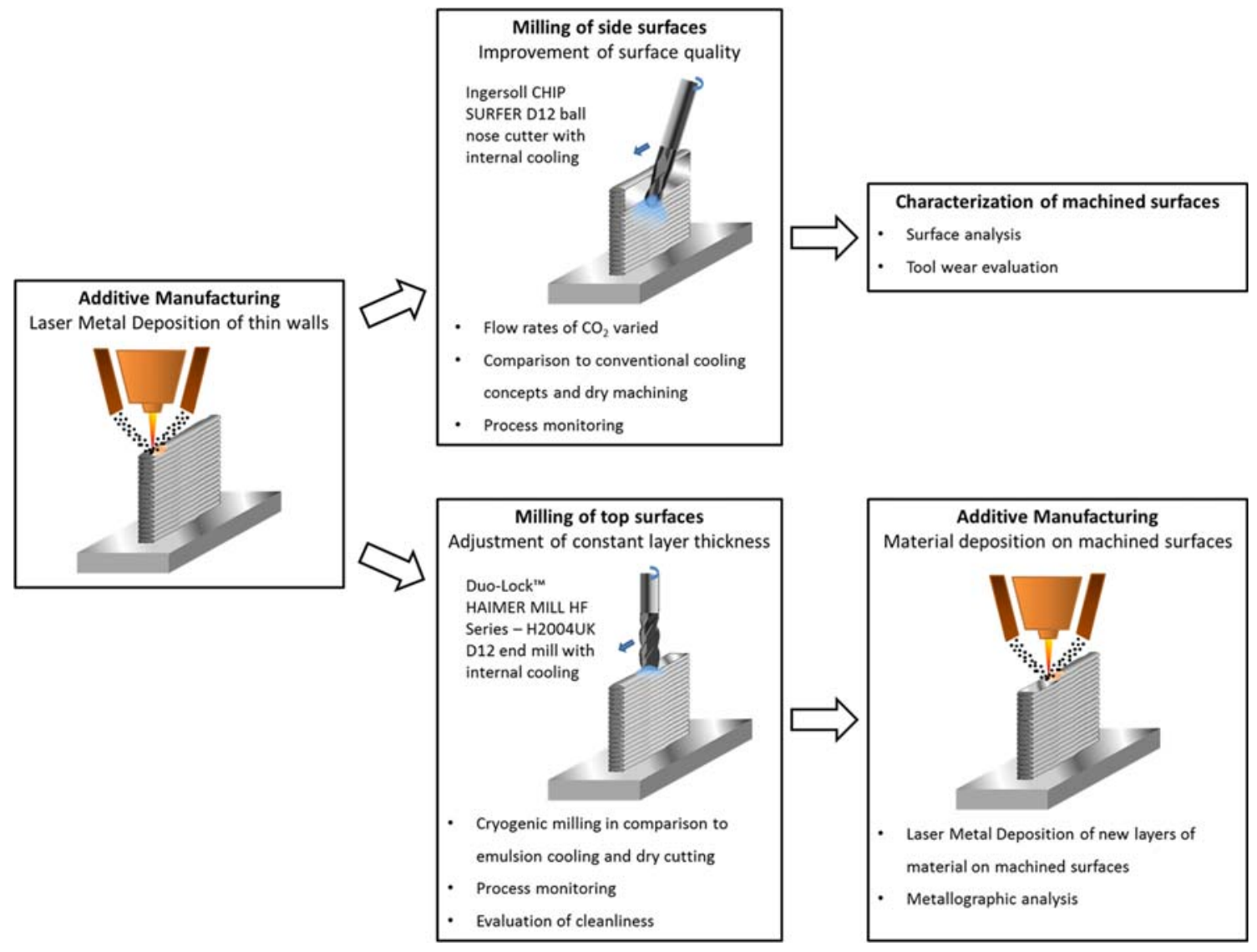

Fig. 3 Flowchart of experimental procedure 

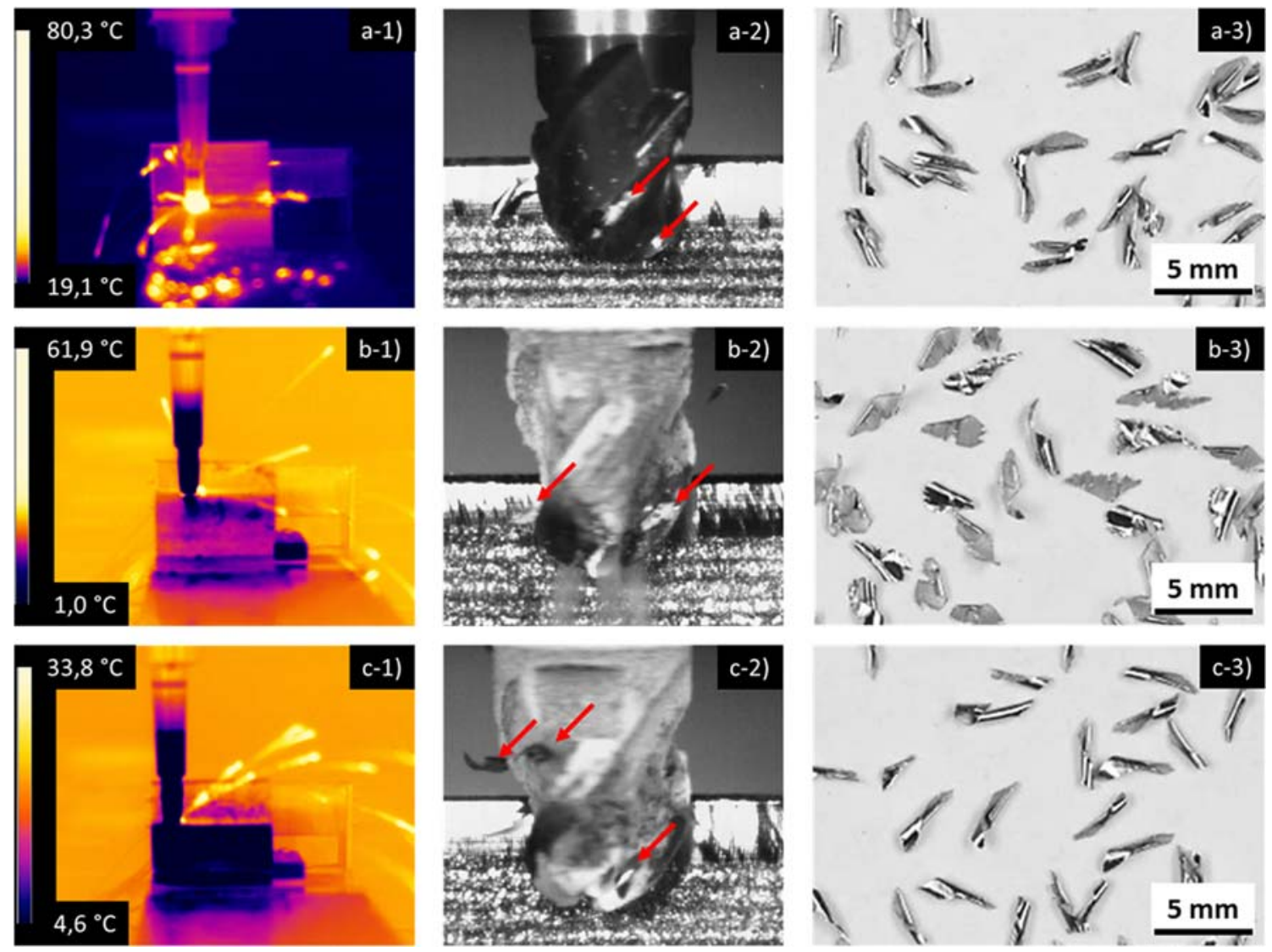

Fig. 4 Process monitoring by means of thermal imaging (1) and high-speed imaging (2) and analysis of produced metal chips (3) during milling of the samples a D-100-side (dry machining), b C45-100-side (cryogenic machining), and c C100-100-side (cryogenic machining)

edges, possibly due to traces of condensed water. In the case of the highest cooling rate, chips even appeared to be frozen to parts of the tool, indicating the high cooling effect and the need of future optimization. Nevertheless, the cutting edge itself remained clean and free of chippings.

\subsection{Chip morphology}

Comparing chip morphology, it is evident that moderate cryogenic cooling resulted in rather flat chips with ragged edges (Fig. 4b-3), whereas Fig. 4 a-3 and c-3 show rolled chips with smoother edges. It seems plausible that the application of cryogenic cooling leads to a decrease in toughness of the material [39] compared to dry machining, causing the chips to have a ragged morphology. However, it was unexpected that chips appeared more regular when cooling was increased further. One potential explanation might be that the increase in mass flow rate of the cryogenic medium decreases the radius of the chip curvature and the chip length, while the larger cooling effect results in higher temperature gradients and thus more pronounced bending stresses [40, 41]. Nevertheless, further investigation would be required in order to fully understand the observed chip morphologies.

\subsection{Tool wear}

Exemplary SEM images of the milling tools (Ingersoll CHIP SURFER D12 ball nose cutter) taken after the tool wear experiments at 50 -fold and 250 -fold magnification are presented in Fig. 3.

In the case of dry machining, tool failure occurred after $59.4 \mathrm{~m}$ in operation, presumably as a consequence of the high thermal load on the tool. Figure 5 a clearly shows the flaking on the cutting edge. Moreover, titanium was found to be adhered or welded to large parts of the cutting edge. This corresponds well to the observations from high-speed imaging. By contrast, the tool operated with cryogenic cooling only showed minor signs of wear even after the pre-defined milling path length of $90 \mathrm{~m}$. Flakings were much smaller and more localized to the outer edge than in the case of dry cutting. Almost no titanium buildup edge was found for cryogenic milling. This fact provides evidence that the tendency of the material to weld to the tool is greatly reduced at these operating temperatures.

The results suggest that tool wear is significantly more pronounced for dry than for cryogenic machining. This assumption is in line with several other studies on cryogenic cooling $[18,22,23]$. Considering that the tool was only used 


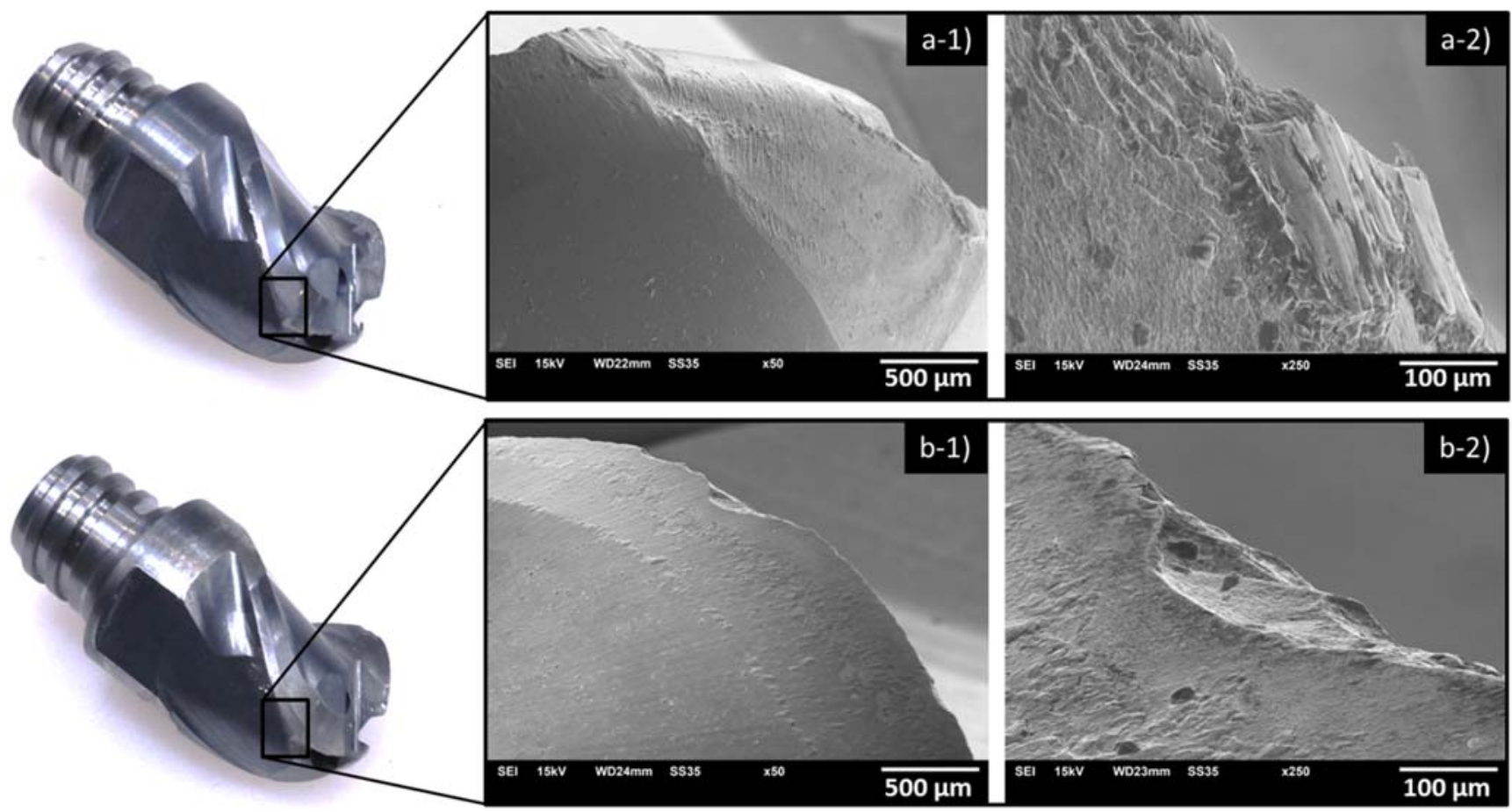

Fig. 5 SEM images of tool wear after a dry machining (59.4-m milling path length, abortion due to tool failure) and $\mathbf{b}$ cryogenic machining (90.0-m milling path length) of the side surfaces at 50-fold and 250 -fold magnification

for a length of roughly $60 \mathrm{~m}$ in dry machining, it can be estimated that tool life during milling of titanium might be increased at least by a factor of 1.5 by means of cryogenic cooling.

\subsection{Surface roughness}

Figure 6 provides an overview of the average roughness values $R_{\mathrm{a}}$ and $R_{\mathrm{z}}$ obtained from tactile roughness measurements.

The overall lowest roughness was found for the samples which had been machined with emulsion cooling. It is assumed that the higher stiffness of the CNC machine had a positive effect on the achievable surface quality. In general, lower roughness values were measured if cryogenic cooling was applied in comparison to dry machining, even though this observation is not statistically significant. Several authors have reported an improvement in surface integrity by means of cryogenic cooling in comparison to conventional machining concepts $[17,19$, 24-27]. It is therefore conceivable that cryogenic milling also resulted in better surface qualities here. Nevertheless, more investigations would be necessary in order to clarify whether this decrease in roughness is really a consequence of cryogenic machining or a coincidence with other influencing parameters. In all cases, higher roughness values were measured if a higher cutting speed had been used. This effect, however, is less pronounced for the samples which had been milled on a conventional CNC milling machine with cooling lubricants. One potential explanation is that the vibrations of both the workpiece and the machine are increased at higher cutting speeds. The milling robot might be more prone to these vibrational effects than the $\mathrm{CNC}$ machine due to the lower stiffness. This is supported by the observation that the standard deviations are considerably higher for those samples.

The images acquired by means of confocal laser scanning microscopy (Fig. 7) allow conclusions regarding the achieved surface quality.

Although the roughness values of the dry machined samples did not differ a lot from the ones attained with cryogenic machining, the three-dimensional reconstruction of the surface suggests that smearing of the titanium took place instead of clean cutting. This resulted in grooves and irregular surface structures in each milled path (Fig. 7a). It is possible that the higher temperatures which occurred during dry cutting in comparison to cryogenic milling lead to softening of the workpiece surface and allowed plastic deformation. Surface damage was presumably aggravated with progressive tool wear. A considerably more homogeneous surface could be achieved with cryogenic machining (Fig. 7b, c). While the surface of the sample C45-100-side still exhibits some irregularities, the milling traces on C100-100-side appear very uniform. These results are in good agreement with a study by Shokrani et al., in which an average reduction in surface roughness of $21 \%$ for cryogenic milling of Ti-6Al-4 V compared to dry machining was found. Moreover, the authors reported that the use 
Fig. 6 Roughness values of milled specimens determined by profilometry
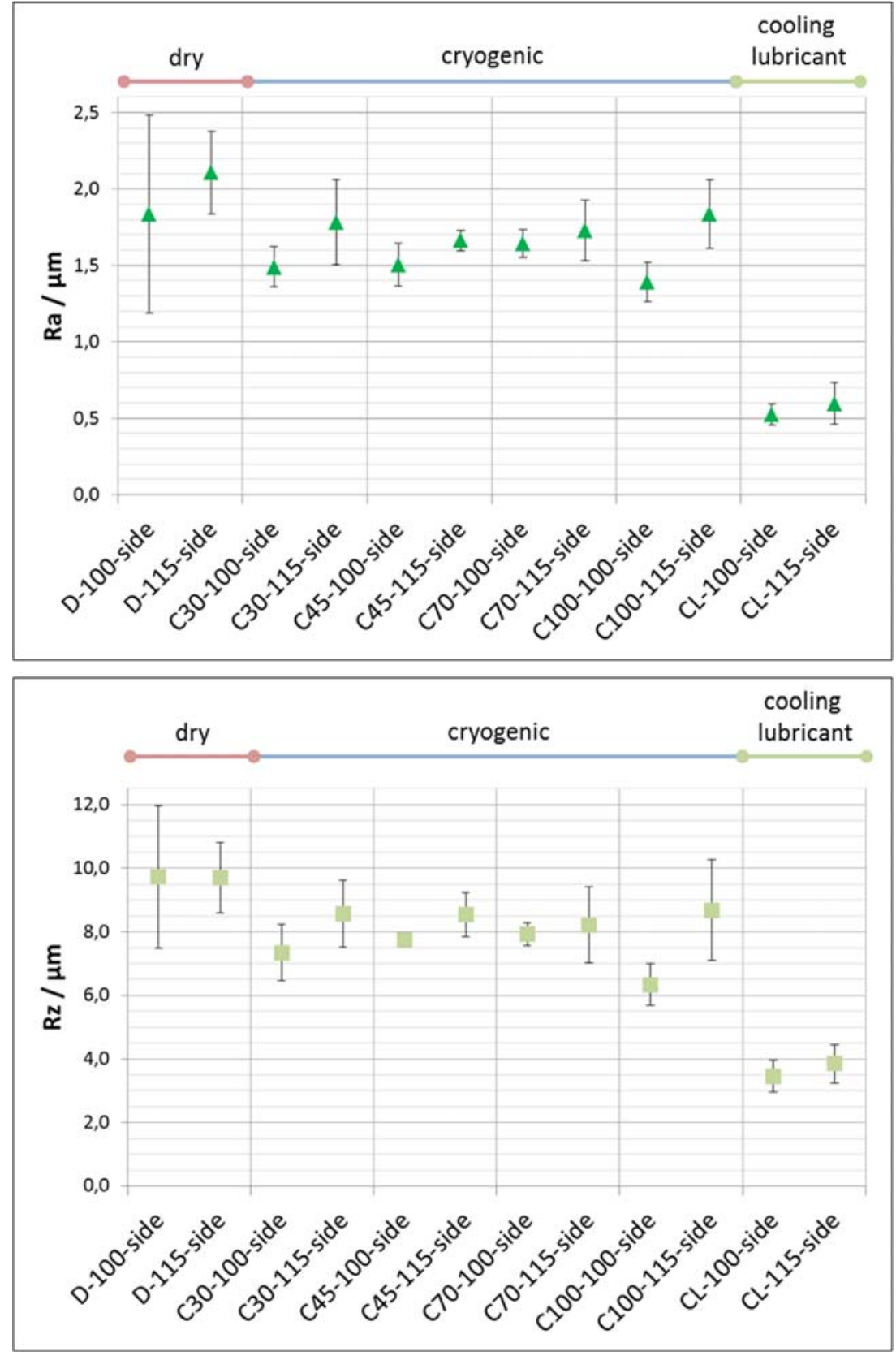

of cryogenic cooling could significantly reduce the occurrence of surface defects after machining, such as smearing, cracks, or chip re-deposition, which were most pronounced after dry machining [27]. Hence, it is conceivable that increased cooling results in a more regular surface and that therefore a better surface quality was achieved at a higher coolant flow rate (Fig. 7b, c). The most homogeneous result was achieved on the specimen CL-100-side (Fig. 7d). On the one hand, this can be ascribed to the optimal cooling and lubricating effect of the cutting fluid, and on the other hand, the higher stiffness of the $\mathrm{CNC}$ machine compared to the robot might have lead to reduced vibrations during machining.

\subsection{Microstructural analysis}

The metallographic cross sections of the milled specimens (Fig. 8) show very similar characteristics independent on the milling parameters.

The image of the milling process (Fig. 8, left) clearly shows the strong icing of tool and sample at high cooling rates (sample C100-100-side). Although no impairment of the surface quality due to this icing could be observed, future research should address the extent to which excessive cooling may have a negative effect on the hybrid manufacturing process and the final component properties. The cross sections of the samples (Fig. 8, right) exhibit a basket-weave microstructure 
Fig. 7 Confocal laser scanning microscopy images of samples a D-100-side (dry machining), b C45-100-side (cryogenic machining), c C100-100-side (cryogenic machining), and $\mathbf{d} \mathrm{CL}$ 100-side (machining with cooling lubricants)
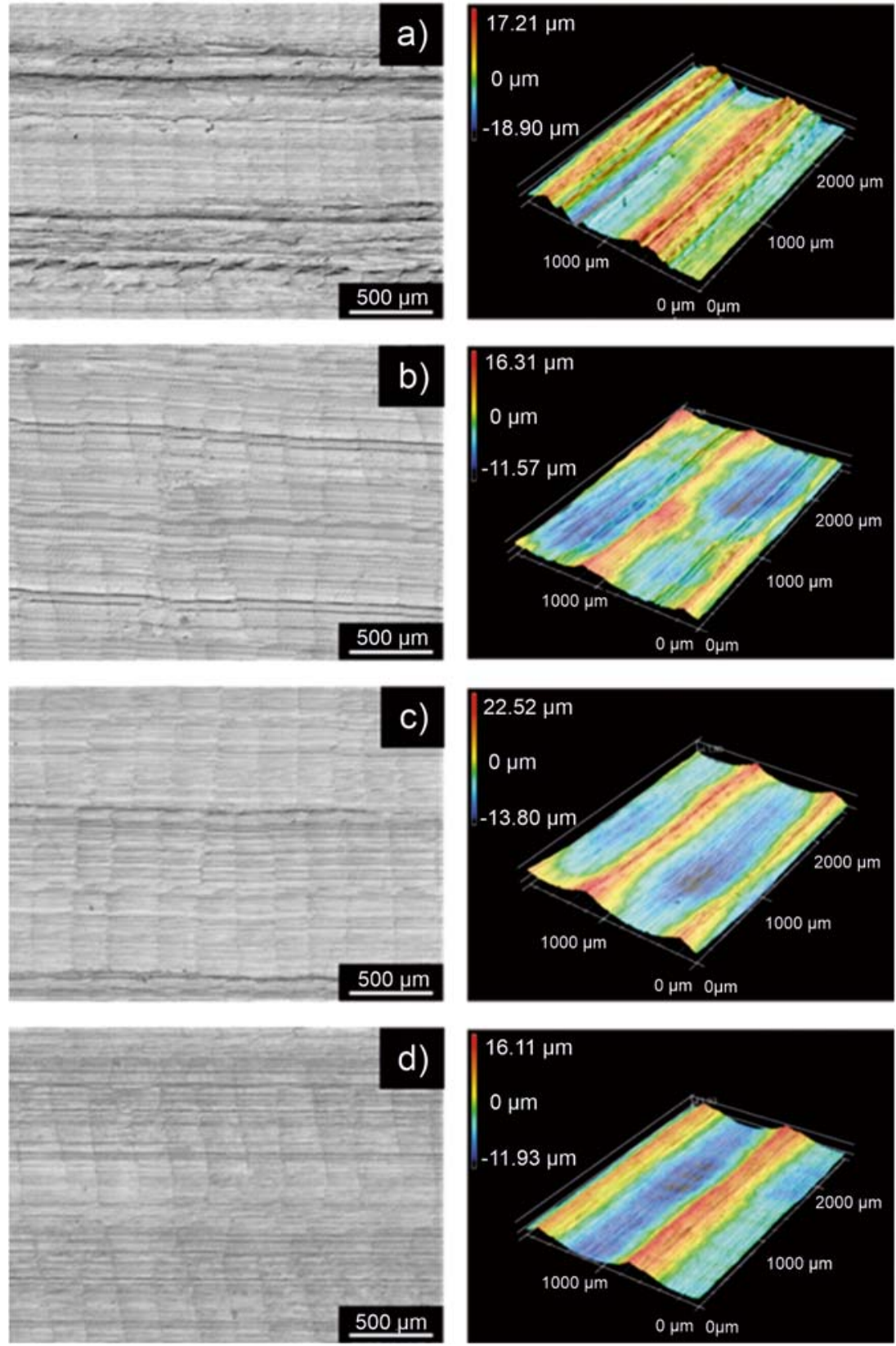

due to the thermal boundary conditions of the additive manufacturing process. This morphology consisting of narrow $\alpha$ laths is typical of Ti-6Al-4V manufactured by LMD as a result of the high cooling rates and is strongly influenced by the process parameters, such as laser power or scanning speed $[42,43]$. Due to the high temperatures and mechanical stresses which occur during machining, severe plastic deformation and phase transformation can often be found in the subsurface area of a material after mechanical processing. Since the thickness of the affected layer is influenced by the machining parameters and the thermal boundary conditions, cryogenic machining was found to reduce the depth of plastic deformation beneath the surface [26]. However, a deformed layer is hard to identify in this case and does not exceed $1 \mu \mathrm{m}$ (Fig. 8). All surfaces were free of cracks. Hence, the cooling strategy did not seem to have a major influence on the surface layer and its microstructure.

\subsection{Cleanliness}

The cleanliness level measured by means of fluorescence analysis on 15 spots per surface on two specimens of each sample group is visualized in Fig. 9.

The significantly highest cleanliness level, which was close to that of the reference sample, was achieved by means of cryogenic machining. The residue-free sublimation of the carbon dioxide 
Fig. 8 Left: Cryogenic machining of side surfaces (an exemplary cross-sectional plane for metallographic analysis is indicated by the dotted line).

Right: SEM images of metallographic cross sections of samples a D-100-side (dry machining), b C45-100-side (cryogenic machining), and $\mathbf{c}$ C100-100-side (cryogenic machining)

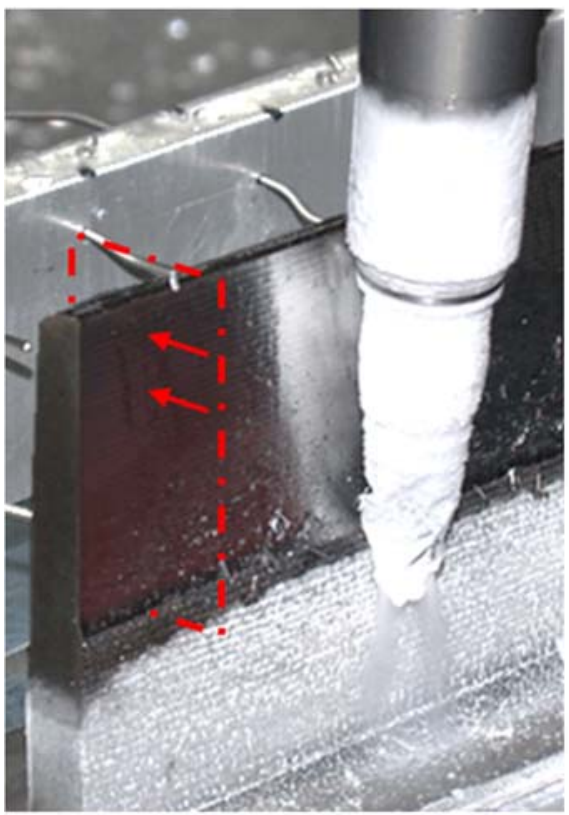

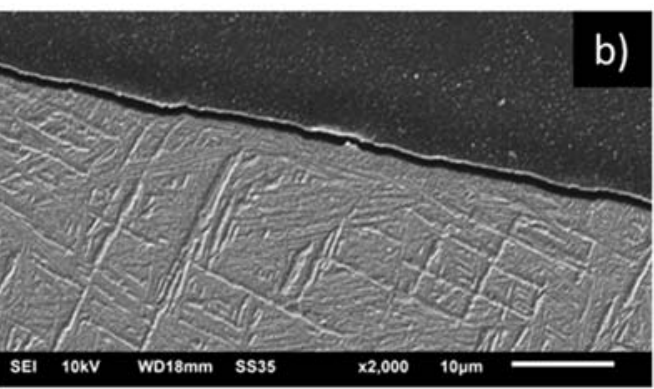

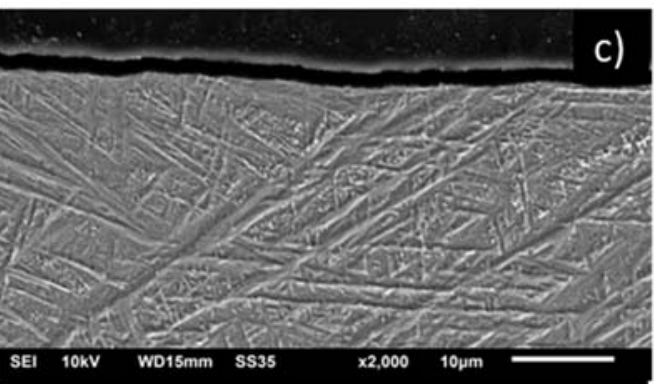

ensured a technically clean surface. In contrast, substantial organic contamination was detected after the use of conventional cooling lubricants. The high statistical deviation is not surprising, since the cutting fluid does not form a homogeneous film on the surface, but is unevenly distributed. Most of the dry machined samples exhibited a good cleanliness level, which was comparable to the value achieved with cryogenic cooling. Nevertheless, conspicuously higher contamination was measured on some spots on the surface. Since no organic medium was used during dry cutting, those findings were surprising and could not be attributed to the machining conditions themselves, but are more likely to be caused by accidental pollution such as dust
Fig. 9 Cleanliness level assessed by means of fluorescence measurements

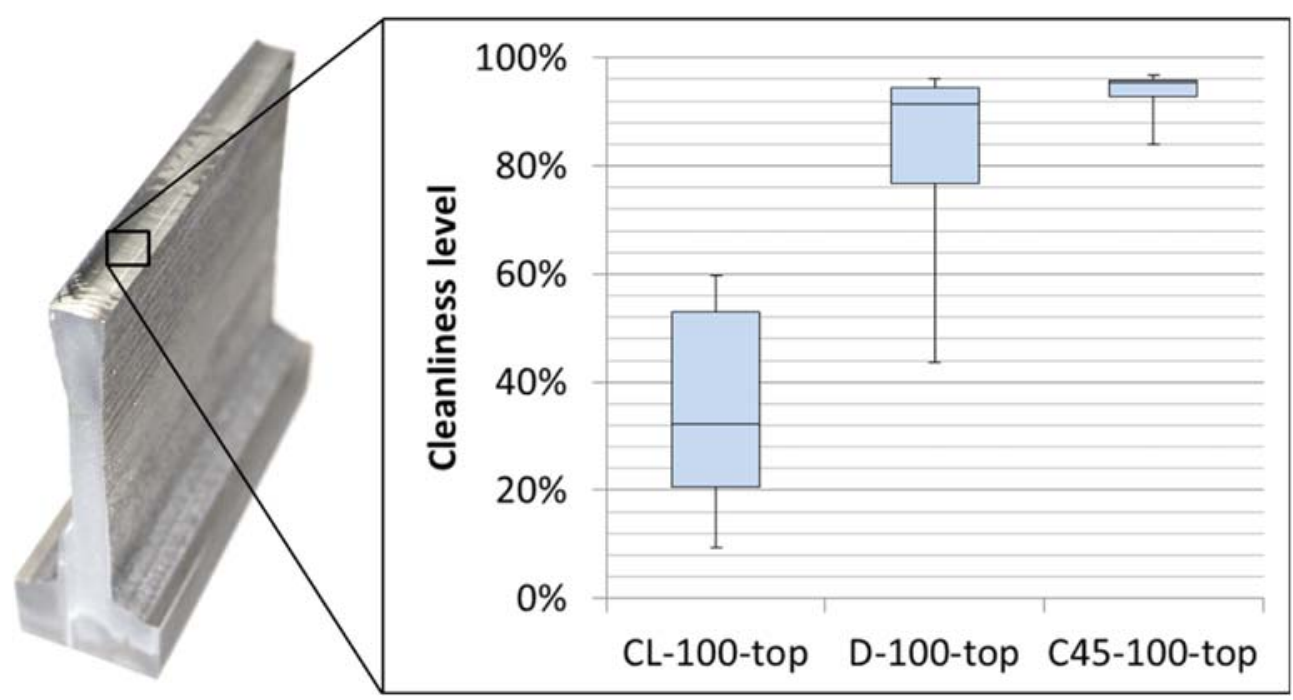


particles. It could be speculated that in the case of cryogenic cooling, the coolant stream flushes away any dust or residual particles, whereas they remain on the surface if no cooling is applied and thus interfere with the fluorescence measurement.

Cortina et al. consider the remains of organic cutting fluids one of the major challenges in hybrid manufacturing, since they can lead to pores during subsequent material buildup and cause damage to the LMD system by contaminating the optical lenses [44]. For this reason, an extensive intermediate cleaning procedure would be required after milling with cooling lubricants in order to achieve sufficient cleanliness of the machined surfaces. On the contrary, the dry and cryogenically machined surfaces exhibit a very high cleanliness level, so an additional cleaning step is not necessary. The omission of intermediate cleaning could considerably shorten the process times in hybrid manufacturing and thus improve the efficiency of the entire process.

\subsection{LMD on machined surfaces}

The influence of residual surface contaminants on subsequent material deposition was investigated on the basis of metallographic cross sections of the deposited weld tracks. Representative results are illustrated in Fig. 10.

The red arrows mark pores within the area of the weld bead and the heat affected zone. In all three cases, debonding occurred at the sides of the weld bead, which is explained by the high reflectivity of the milled surfaces in combination with the intensity drop of the applied laser beam with a Gaussian distribution. Apart from the lack of fusion, only minor defects could be observed in the dry and cryogenically milled samples (Fig. 10b, c). By contrast, a considerable number of pores were found in the sample with residues of cooling lubricant (Fig. 10a). One explanation might be that the residues of the cooling lubricant evaporate abruptly due to the heat input during LMD. However, the gasses cannot escape from the melt pool because of the rapid solidification and thus lead to process instabilities and defects. These findings are in line with the observations reported by Yan et al., which also show the occurrence of pores and cracks when material is deposited on a surface which is contaminated with cooling lubricant residues. The authors also observed a decrease in tensile strength of hybrid manufactured specimens using emulsion cooling compared to reference specimens without coolant if no appropriate cleaning step was performed [35]. It seems conclusive that the existence of defects also might have a negative effect on other component properties such as fatigue behavior. Cortina et al. investigated the porosity within the weld beads of Inconel 718 deposited by means of LMD on additively manufactured substrates, which had been impregnated with water/cooling lubricant emulsions of different concentrations. Their results clearly show a correlation between higher degrees of mineral oil
Fig. 10 Left: Weld track deposited by means on LMD on milled surface (an exemplary cross-sectional plane for metallographic analysis is indicated by the dotted line). Right: cross section of weld track on surface of sample a CL-100top, b D-100-top, and c C45-100top. Pores are marked by red arrows

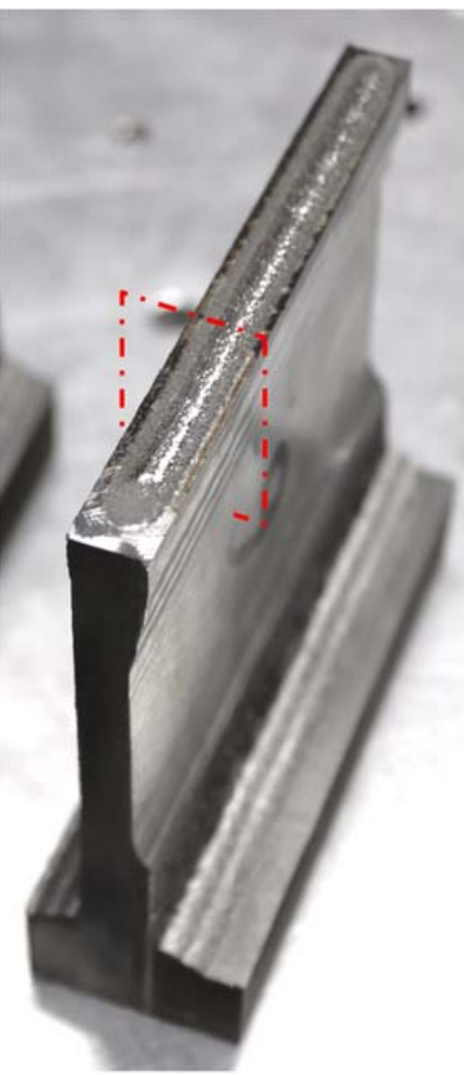

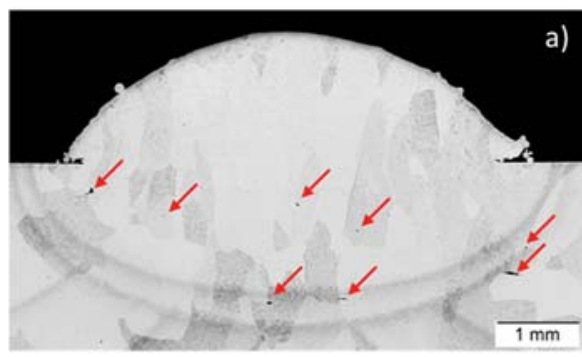
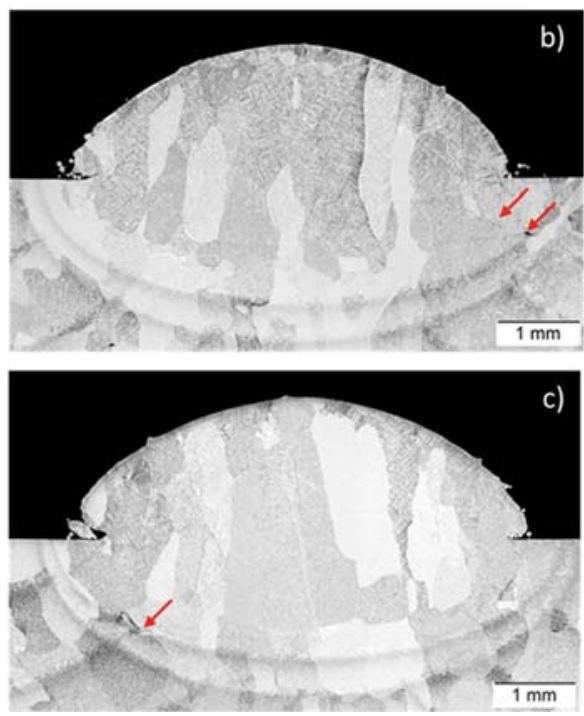
residues and increased porosity in the weld bead. The authors further outline the importance of intermediate cleaning steps, preferably by laser cleaning, prior to the deposition of new layers of material. Especially for higher concentrations of cooling lubricants, laser cleaning was the only way to achieve acceptable surface conditions for further LMD, even though porosity could not be fully avoided [36]. These results, together with the analysis of the surface cleanliness level, strongly suggest that the use of conventional cutting fluids negatively affects the deposition of new material [44] and is therefore not suitable for hybrid manufacturing without a qualified cleaning process. Conversely, both dry and cryogenic intermediate machining can lead to a good bonding of the subsequent layer even without an additional cleaning step, provided that appropriate parameters for additive manufacturing are used on the milled surfaces.

Hence, cryogenic machining is a highly promising technology for hybrid manufacturing of hard-to-cut materials, since it enhances surface integrity and tool life in comparison to dry cutting and results in almost contamination-free surfaces, which facilitate a defect-free material buildup even without additional cleaning procedures. This might be particularly relevant for large-sized or complex components which require intermediate machining, e.g., due to undercuts or other features which are difficult to access on the finished part. In addition, additive manufacturing is often used in the extension or repair of existing components. Cryogenic machining could also be used here, for example, to mill away damaged component areas before the additive manufacturing step without the need for additional cleansing.

Two milling strategies were followed in this study, namely, milling of the side surfaces and the top surfaces of the additively manufactured parts. Depending on the application, both strategies could be relevant in practice, whereby the former is primarily used to adjust the surface quality of component areas that will later no longer be accessible, while the latter serves to ensure a suitable substrate surface for the LMD process [32]. In both cases, cryogenic machining could be a suitable alternative to conventional machining concepts. Especially in contrast to the use of cooling lubricants, intermediate cleaning steps can be omitted in hybrid processing, making the entire process more efficient. Cryogenic cooling also eliminates the problem of environmental and health hazards associated with mineral oil-based lubricants.

Potential applications of the presented approach are seen in space and aviation industries or the medical sector, where the absence of defects and impurities is highly important. The next steps should include the identification and verification of optimal parameters for cryogenic milling, as the results from process monitoring and surface analysis indicated that both too little and too excessive cooling might be detrimental. Open questions include the influence of condensation water on the subsequent material deposition or the dimensional accuracy of the final component. Future work also requires the setup of a stable and reproducible hybrid manufacturing process using cryogenic milling and the thorough investigation of resulting material properties, such as tensile strength and fatigue behavior.

\section{Conclusions}

In this paper, the suitability of cryogenic milling with carbon dioxide for hybrid manufacturing approaches was assessed. Milling experiments were performed on additively manufactured Ti-6Al-4V samples with either no cooling or with liquid $\mathrm{CO}_{2}$ or mineral oil-based cutting fluids as cooling mediums, respectively.

It could be shown that cryogenic machining offers considerable advantages over dry machining in terms of achievable surface quality and tool life. This could be proven by the reduction of surface roughness and surface defects on the milled surfaces and by the qualitative analysis of the tool damage after a defined milling path length.

The main advantage of cryogenic milling over the use of cooling lubricants is the avoidance of organic residues on the machined surfaces. The absence of such contaminations on cryogenically machined surfaces was proven by fluorescence analysis. This is particularly important for hybrid manufacturing, where additional material is deposited on the milled surfaces in an additive manufacturing step. In this study, weld tracks were applied on the processed surfaces by laser metal deposition. While cooling lubricant residues led to porosity in the subsequent layer, the technically clean surfaces after dry or cryogenic machining allowed an almost defect-free material deposition.

Future research should address the mechanical properties of components produced in a hybrid approach using cryogenic cooling. Moreover, the optimal cooling parameters need to be verified in order to achieve a stable and reproducible hybrid manufacturing process, which can be scaled up to larger component dimensions.

Potential applications might be the repair and fabrication of highly complex parts, especially in the aerospace and biomedical sector.

Funding information Open Access funding provided by Projekt DEAL. This research was partially funded by the European Space Agency (ESA) as part of the project $\mathrm{AO} / 1-8607 / 16 / \mathrm{NL} / \mathrm{LvH}$. Their financial support is greatly acknowledged.

\section{Compliance with ethical standards}

Conflict of interest The authors declare that they have no conflict of interest. 
Open Access This article is licensed under a Creative Commons Attribution 4.0 International License, which permits use, sharing, adaptation, distribution and reproduction in any medium or format, as long as you give appropriate credit to the original author(s) and the source, provide a link to the Creative Commons licence, and indicate if changes were made. The images or other third party material in this article are included in the article's Creative Commons licence, unless indicated otherwise in a credit line to the material. If material is not included in the article's Creative Commons licence and your intended use is not permitted by statutory regulation or exceeds the permitted use, you will need to obtain permission directly from the copyright holder. To view a copy of this licence, visit http://creativecommons.org/licenses/by/4.0/.

\section{References}

1. Bourell DL (2016) Perspectives on additive manufacturing. Annu Rev Mater Res 46:1-18. https://doi.org/10.1146/annurev-matsci070115-031606

2. Ghidini T, Pambaguian L, Blair S (2015) Joining the third industrial revolution: 3D printing for space. European Space Agency Bulletin 2015(163):24-33

3. Ghidini T (2018) Materials for space exploration and settlement. Nat Mater 17(10):846-850. https://doi.org/10.1038/s41563-0180184-4

4. Grimm T, Wiora G, Witt G (2015) Characterization of typical surface effects in additive manufacturing with confocal microscopy. Surf Topogr: Metrol Prop 3(1):14001. https://doi.org/10.1088/ 2051-672X/3/1/014001

5. Flynn JM, Shokrani A, Newman ST et al (2016) Hybrid additive and subtractive machine tools - research and industrial developments. Int J Mach Tools Manuf 101:79-101. https://doi.org/10. 1016/j.ijmachtools.2015.11.007

6. Jones JB (2014) The synergies of hybridizing CNC and additive manufacturing. RAPID 2014 conference and exposition; Detroit. TP14PUB72. Online: http://www.hybridmanutech.com/uploads/2/ 3/6/9/23690678/2014_jones_hybridizing_cnc_am_authors version_of_sme_tp14pub77_.pdf

7. VDI (2016) Handlungsfelder - Additive Fertigung (Fields of Action - Additive Manufacturing) 2016. www.vdi.de/HandlungsfelderAM

8. Pramanik A, Littlefair G (2015) Machining of titanium alloy (Ti6Al-4V) - theory to application. Mach Sci Technol (19):1-49. https://doi.org/10.1080/10910344.2014.991031

9. Lopez de Lacalle LN, Perez-Bilbatua J, Sanchez JA et al (2000) Using high pressure coolant in the drilling and turning of low machinability alloys. Int J Adv Manuf Technol (16):85-91. https://doi. org/10.1007/s001700050012

10. Wang F, Wang Y (2019) Effect of cryogenic cooling on adiabatic shearing in processing titanium alloy. Int J Adv Manuf Technol 102(9-12):3587-3596. https://doi.org/10.1007/s00170-01903380-3

11. Hong SY, Ding Y (2001) Cooling approaches and cutting temperatures in cryogenic machining of Ti-6Al-4V. Int J Mach Tools Manuf 41(10):1417-1437. https://doi.org/10.1016/S08906955(01)00026-8

12. Ezugwu EO, Wang ZM (1997) Titanium alloys and their machinability - a review. J Mater Process Technol (68):262-274. https:// doi.org/10.1016/S0924-0136(96)00030-1

13. Leyens C, Peters M (2010) Titanium and titanium alloys: fundamentals and applications. Wiley-VCH, Weinheim, Chichester. https://doi.org/10.1002/3527602119

14. Moser KD (1999) The manufacture and fabrication of tantalum. JOM 51(4):29-31. https://doi.org/10.1007/s11837-999-0076-9
15. Lee C, Choi Y, Ha J et al (2017) Eco-friendly technology for recycling of cutting fluids and metal chips: a review. Int $\mathrm{J}$ of Precis Eng and Manuf-Green Tech 4(4):457-468. https://doi.org/ 10.1007/s40684-017-0051-9

16. Benedicto E, Carou D, Rubio EM (2017) Technical, economic and environmental review of the lubrication/cooling systems used in machining processes. Procedia Engineering 184:99-116. https:// doi.org/10.1016/j.proeng.2017.04.075

17. Debnath S, Reddy MM, Yi QS (2014) Environmental friendly cutting fluids and cooling techniques in machining: a review. J Clean Prod 83:33-47. https://doi.org/10.1016/j.jclepro.2014.07.071

18. Jawahir IS, Attia H, Biermann D et al (2016) Cryogenic manufacturing processes. CIRP Ann 65(2):713-736. https://doi org/10.1016/j.cirp.2016.06.007

19. Bordin A, Medeossi F, Ghiotti A et al (2016) Feasibility of cryogenic cooling in finishing turning of acetabular cups made of additive manufactured Ti6A14V. Procedia CIRP 46:615-618. https:// doi.org/10.1016/j.procir.2016.04.029

20. Cordes S, Hübner F, Schaarschmidt T (2014) Next generation high performance cutting by use of carbon dioxide as cryogenics. Procedia CIRP (14):401-405. https://doi.org/10.1016/j.procir. 2014.03.091

21. Isakson S (2018) Cryogenic machining of Ti-6Al-4V. Thesis for the degree of licentiate of engineering, Chalmers University of Technology. Online: https://research.chalmers.se/publication/ 503255/file/503255_Fulltext.pdf

22. Ayed Y, Germain G, Melsio AP, Kowalewski P, Locufier D (2017) Impact of supply conditions of liquid nitrogen on tool wear and surface integrity when machining the Ti-6Al-4V titanium alloy. Int J Adv Manuf Technol 93(1-4):1199-1206. https://doi.org/10. 1007/s00170-017-0604-7

23. Biermann D, Abrahams H, Metzger M (2015) Experimental investigation of tool wear and chip formation in cryogenic machining of titanium alloys. Adv Manuf 3(4):292-299. https://doi.org/10.1007/ s40436-015-0122-5

24. Bordin A, Bruschi S, Ghiotti A et al (2015) Analysis of tool wear in cryogenic machining of additive manufactured Ti6Al4V alloy. Wear 328-329:89-99. https://doi.org/10.1016/j.wear.2015.01.030

25. Bruschi S, Bertolini R, Bordin A et al (2016) Influence of the machining parameters and cooling strategies on the wear behavior of wrought and additive manufactured Ti6Al4V for biomedical applications. Tribol Int 102:133-142. https://doi.org/10.1016/j. triboint.2016.05.036

26. Kaynak Y, Lu T, Jawahir IS (2014) Cryogenic machining-induced surface integrity: a review and comparison with dry, MQL, and flood-cooled machining. Mach Sci Technol (18):149-198. https:// doi.org/10.1080/10910344.2014.897836

27. Shokrani A, Dhokia V, Newman ST (2016) Investigation of the effects of cryogenic machining on surface integrity in $\mathrm{CNC}$ end milling of Ti-6Al-4V titanium alloy. J Manuf Process 21:172179. https://doi.org/10.1016/j.jmapro.2015.12.002

28. Bertolini R, Lizzul L, Pezzato L, Ghiotti A, Bruschi S (2019) Improving surface integrity and corrosion resistance of additive manufactured Ti6Al4V alloy by cryogenic machining. Int J Adv Manuf Technol 104(5-8):2839-2850. https://doi.org/10.1007/ s00170-019-04180-5

29. Liu R, Wang Z, Sparks T et al. (2017) Aerospace applications of laser additive manufacturing. In: Brandt $\mathrm{M}$ (ed) Laser additive manufacturing: Woodhead publishing series in electronic and optical materials. Woodhead publishing, pp 351-371. doi: https://doi. org/10.1016/B978-0-08-100433-3.00013-0

30. Brueckner F, Riede M, Müller M et al (2018) Enhanced manufacturing possibilities using multi-materials in laser metal deposition. Journal of Laser Applications 30(3):32308. https://doi. org/10.2351/1.5040639 
31. Boivie K, Dolinsek S, Homar D (Prague 2011) Hybrid Manufacturing; Integration of Additive Technologies for Competitive Production of Complex Tools and Products. 15th International Research/Expert Conference "Trends in the Development of Machinery and Associated Technology" (https:// www.researchgate.net/publication/267226211_HYBRID MANUFACTURING INTEGRATION OF ADDITIVE TECHNOLOGIES FOR COMPETITIVE PRODUCTION OF_COMPLEX_TOOLS_AND_PRODUCTS)

32. Sealy MP, Madireddy G, Williams RE et al (2018) Hybrid processes in additive manufacturing. J Manuf Sci Eng 140. https://doi.org/ $10.1115 / 1.4038644$

33. Karunakaran KP, Suryakumar S, Pushpa Vet al (2009) Retrofitment of a CNC machine for hybrid layered manufacturing. Int J Adv Manuf Technol 45(7-8):690-703. https://doi.org/10.1007/s00170009-2002-2

34. Du W, Bai Q, Wang Y et al (2018) Eddy current detection of subsurface defects for additive/subtractive hybrid manufacturing. Int $\mathrm{J}$ Adv Manuf Technol 95(9-12):3185-3195. https://doi.org/10.1007/ s00170-017-1354-2

35. Yan L, Zhang Y, Newkirk J et al (2018) Investigation of machining coolant residue cleaning methods for Ti6Al4V part fabrication through hybrid manufacturing process. Manuf Lett (16):10-13. https://doi.org/10.1016/j.mfglet.2018.02.016

36. Cortina M, Arrizubieta JI, Ukar E et al (2018) Analysis of the influence of the use of cutting fluid in hybrid processes of machining and laser metal deposition (LMD). Coatings 8(2):61. https://doi. org/10.3390/coatings8020061

37. Seidel A, Finaske T, Brueckner F (2019) Verfahren zur Beeinflussung der Mikrostruktur eines Zusatzwerkstoffgefüges eines Zusatzwerkstoffs, der beim schichtweisen Laserauftragschweißen auf ein Substrat oder mindestens einer bereits aufgebrachten Schicht des Zusatzwerkstoffs und/oder der Vermeidung einer Randzonenversprödung des dabei aufgetragenen Zusatzwerkstoffs (Process for influencing the microstructure of an additive structure of a filler material, which is formed during layerwise laser cladding on a substrate or at least one already applied layer of the filler material and/or the avoidance of marginal zone embrittlement of the filler material applied thereby)(EP 3498402 A1)

38. Kolsch N, Seidel A, Finaske T et al. (2019) A Novel Local Shielding Approach for the Laser Welding Based Additive Manufacturing of Large Structural Space Components from Titanium. International Congress on Applications of Lasers and Electro-Optics - ICALEO 2019. - Orlando, Fl.: LIA (https://www. researchgate.net/publication/336317995 A Novel Local Shielding_Approach_for_the_Laser_Welding_Based_Additive_ Manufacturing_of Large_Structural_Space_Components_from Titanium_Paper_000107_-_ICALEO_Conference_2019)

39. Muiruri AM, Maringa M, Du Preez WB et al (2018) Variation of impact toughness of as-built DMLS Ti6Al4V (ELI) specimens with temperature. SAJIE 29(3). https://doi.org/10.7166/29-3-2076

40. Emel'yanov SG, Yatsun EI, Remnev AI et al (2011) Chip curling in metal cutting. Russ Eng Res 31(7):679-683. https://doi.org/10. 3103/S1068798X11060086

41. Pervaiz S, Kannan S (Toronto 2018) FEM Assisted Observations of Cutting Forces, Temperature and Chip Curling in Oblique Machining. Proceedings of The Canadian Society for Mechanical Engineering International Congress. https://doi.org/10.25071/ $10315 / 35234$

42. Ren YM, Lin X, Fu X et al (2017) Microstructure and deformation behavior of Ti-6Al-4V alloy by high-power laser solid forming. Acta Mater 132:82-95. https://doi.org/10.1016/j.actamat.2017.04. 026

43. Wu X, Liang J, Mei J et al (2004) Microstructures of laser-deposited Ti-6Al-4V. Mater Des 25(2):137-144. https://doi.org/10.1016/j. matdes.2003.09.009

44. Cortina M, Arrizubieta JI, Ruiz JE, Ukar E, Lamikiz A (2018) Latest developments in industrial hybrid machine tools that combine additive and subtractive operations. Materials (Basel) 11(12). https://doi.org/10.3390/ma11122583

Publisher's note Springer Nature remains neutral with regard to jurisdictional claims in published maps and institutional affiliations. 